\title{
Identification and Analysis of Problem of Word Recognition in Reading among JSS Students in Gwgwalada and Kwali Area Councils of Federal Capital Territory, Abuja
}

\author{
Immaculate Nkechi Don-Ezenne \\ Department of General Studies, School of Education, Federal Capital Territory College of Education Zuba, \\ P.M.B. 61, Garki, Abuja, Nigeria
}

\begin{abstract}
This study was designed to identify and analyse problem of word recognition in reading among junior secondary school (JSS) students in Gwagwalada and Kwali Area Councils of Federal Capital Territory (FCT), Abuja. The study adopted a survey research design. The population for the study was 4,535 JSS II students. 3 research questions and 2 null hypotheses were formulated to guide the study. The instruments used for data collection was English language reading passage developed by the researcher. To ensure validity of the instrument, the instrument was subjected to face validation by English language teachers in FCT College of Education Zuba, Abuja. The reliability coefficient computed for the instrument was found to be 0.75 using Cronbach Alpha formula. Frequency and Mean was used to answer the research questions; while t-test statistics was employed to test the hypotheses at 0.05 level of significance. The study found out that that the junior secondary school students committed errors in word recognitions during reading and male students had more problems in word recognitions during reading than the female students. The study also found out that there was no significant difference between the errors committed by male and female students in reading. Consequently, it was recommended among others that stakeholders in education should provide facilities like library and teaching aids that can encourage students reading competence and improve their performance in English language. Teachers should pay particular attention to the teaching of reading in English Language.
\end{abstract}

Key words: Analysis, Word Recognition, Reading and Junior Secondary School Students

\section{Introduction}

The strong relationship between education and national development has been persistently reflected in the huge amount of money which governments commit to the educational sector as well as the myriad of conferences and researches directed toward the improvement of education. Similarly, the gap between developed and developing nations has been associated with differences in the level of education and literacy rates in those nations. Therefore, education can be used as a tool to achieve national development and increase literacy level in Nigeria.

In view of the above and the need to promote literacy and communication in the society, the Federal Government of Nigeria emphasized in the National Policy on Education that "English language shall be taught as a social subject for the first three years of pupils in primary schools, while it shall be the medium of instruction from the fourth year of pupils in primary schools" (Federal Republic of Nigeria, 2004). The same policy stressed further that English shall be the medium of communication or teaching in Upper Basic (Junior Secondary) School. English language as a school subject is recognized as the foundation of all subjects. This emphasizes the importance of English language at all levels of education and a reason for making English language compulsory as one of the core subjects in the primary and secondary school curricula. Furthermore, the National Universities Commission (NUC) pointed out that a credit pass in English language at Senior Secondary School Examination (SSCE) is a requirement for admission into any course in Nigerian Universities. Hence, a failure in it is a major obstacle for admission into the University and even getting a job. This probably explains the need for endless research and the development of this all-important subject matter.

Language is a means by which feelings and cultures of a race can be communicated from one member of the race to another or to people from different backgrounds in order to achieve purpose of communication. Language is essential for satisfactory relationship with other people. Once a child can express himself, confidence appears to increase greatly. In learning a language, there are four basic skills that are needed for complete communication (Cyan, 2005). When learning a native language, the learner usually learn to listen first, then to speak, read, and finally write.

Reading is a multifaceted process involving word recognition, comprehension, fluency, and motivation. Reading is making meaning from print. It requires identifying the words in print - a process called word recognition, constructing an understanding from them - a process called comprehension and coordinating the identifying words and making meaning so that reading is automatic and accurate - an achievement called 
fluency. The reading components as explained by literacy and information communication includes Word Analysis (phonics), Word Recognition, Fluency and Word Meaning,

Reading skills according to Hamptson 1999 enable the reader to turn writing into meaning and achieve the goals of independence comprehension, and fluency. He explained further that reading skills are specific abilities which enable a reader to read the written form as meaningful language to read anything written with independence comprehension and fluency and to mentally interact with the message reading is the understanding of language by interpreting writing symbols for speech sounds (Offorma 2009) it involves forming character letters or word on a surface it is the highest and most complex of the language skills therefore a good reader must be able to recognize words correctly pronounce the words accurately and read them fluently. Word recognition is the ability of a reader to recognize written words correctly and virtually effortlessly. It is sometimes referred to as isolated word recognition because it entails a readers ability to recognize words individually without the benefit of surrounding words for contextual help (Andrew 2010;2)

Reading skills are one out of four English language skills those teachers who make any attempt to teach reading only come to the class to direct the student on the topics and the number of chapters to read the reasons for these are obvious. The inherent nature of the reading skills is what scares both the students and teachers from learning and using important skills. Like the other language skills reading is a higher order skill in language development. It is not required informally but taught by one who is knowledgeable in it. Definite efforts must be made to guide the learners to master expressions, pronunciation, spelling and dictation. However this is not a very easy task for the teachers and student to attain because of the complex nature of the skills.

The reading problems of English language learners have become one of the most important issues in all of educational policy and practice. To "Read" according to the Longman Dictionary of contemporary English (2009) is "to look at written words and understand what they mean". Reading is the cognitive process of understanding a written linguistic message. Reading skills enable readers to turn writing into meaning and achieve the goals of reading. Reading comprehension is the process of understanding and constructing meaning from a piece of text. In upper basic school, the demands placed on children in the classrooms during reading lessons are enormous. However, no task is more challenging in those early years of school than learning to read. Reading requires children to accurately use all of their language, decoding, phonetic and visual skills to successfully recognize words and gather meaning from the written text. Unfortunately, about $40 \%$ of schoolaged children in Nigeria are struggling to read (Foluso, 2004). Some of these children suffer from reading problems such as vocabulary development, difficulty in concept building, organizing information and facts and selecting collateral reading and related source materials. However, a large portion of children struggling to read are having difficulties in their phonetic awareness and language processing (Deluxe, 2004)

In the last ten years, important progress has been made in understanding the earliest stages of reading acquisition in English language (Emeteran 1991 \& Ijaiya 1997). The teaching of reading has gained the attention of researchers for obvious reasons every child needs to become fully competent in reading in order to succeed in school and to discharge responsibilities as a citizen of a democratic society. A citizen who reads has the capacity to actively participate in the community of learners.

Reading is the foundation of much of the enjoyment the individual gets out of life and is closely related to vocational efficiency. Emetaran $(1991 ; 33)$ noted that reading provides a a back up of information which reduces ignorance thus empowering and promoting literacy and communication, it is understandable then that much attention has been devoted to the improvement of reading instruction, yet in many urban, semi-rural and rural schools large and growing numbers of children are reaching upper basic schools levels and are unable to read and understand appropriate materials (Foluso 2004;3). The result of the FME/UNICEF/UNESCO/MLA study of 1997 (Falujo, Makoju,Okebukola, Olabodun \&Onuche,1997) revealed that less than a quarter of primary school students in Nigerian schools are unable to read and comprehend texts written in English. However, Okebukola (2000) argued that primary school pupils in urban areas are better in reading than primary school pupils in rural areas. This study will therefore; make an attempt to find out if this difference in reading is as a result of students' location.

Hornby (2009) defined location as a place where something happens or exists. In this study, the location will be classified into rural and urban. In a study carried out by Akabogu (as cited in Offorma, 2009) on contextual clue exposure to English registers using step by step procedure, it was revealed that contextual clue exposure to English registers significantly enhanced students' achievement in reading comprehension than the conventional method of background knowledge of text. There was also significant effect of location on students' achievement in reading comprehension. In a similar vein, Aboki and Oyetunde (1998) observed that students in urban areas performed better students in rural areas due to poor reading habits of the students, non-conducive learning environment and non availability of necessary tools that enhance reading and writing skills in rural areas.

The issue of gender and students' achievement in English language has also been of interest to researchers. Gender refers to roles, attitudes and values assigned by culture and society to men and women. 
These roles, attitudes and values define the behaviour of men and women and the relationship between them (Oyedeji, 2004). Roles, attitudes and values are created and maintained by social institutions such as families, government, communities, schools, churches, mosques and media. Because of gender, certain roles, traits and characteristics are assigned or ascribed distinctly and strictly to men or to women. Gender influence on students' achievement has been a common intervening variable of studies. However, while some studies observed that female students performed better than male students in the English language (Bukoye, 2000; Cyan, 2005), other group of researchers submitted that gender has no significant effect on students' achievement (Becky, 1991; Onibokun, 1980). In a study carried out by Akabogu, (as cited in Offorma 2009), it was revealed that there was no significant effect of gender on students' achievement in reading skills. Hence, an attempt will be made in this study to find out if these disparities are in reading skills.

The need to inculcate into the students the reading skills which will enable them to communicate effectively and promote literacy, make the researcher to identify and analyze reading problems among junior secondary school students. Identification according to Hornby (2009) is the process of recognizing factors that are responsible for something. In the contexts of this study identification is the process of recognizing those factors that are responsible for reading inability of upper basic school students. While analysis according to him is a careful examination of the problems in order to understand more about them.

Some researchers have carried out studies on problem areas in English language at primary school level. For instance, Folusho (2004) carried out a research on children's emergent reading in English language from theory to practice. The result shows that more than $80 \%$ of all the pupils were psychologically, socially, emotionally and linguistically ready in their L1 for reading task. It was further revealed that almost $80 \%$ of the pupils who were involved in the study have had contact with English language. Ajuziem (1991) also carried out a research on identification of problems in the implementation of English language curriculum. Her study covered samples of secondary schools in Imo state using descriptive survey method. Ajuziem identified lack of infrastructural facilities, poor funding and poor teaching methods as some of the factors responsible for poor implementation of English language curriculum. A similar study was also conducted by Baldeh (1999) o the identification and analysis of special learning problem in reading and writing among primary school pupils in Anambra State Nigeria. The authors identified hesitation over words or sentences and stammering as special learning problems in reading and writing among primary school pupils in Imo state. Despite the significant result recorded in provision of instructional materials in other areas of English language, students in junior secondary schools can still not be able to read and write. It is on this basis that the researcher tends to identify and analyse the reading problems among junior secondary school students.

\section{Statement of the Problem}

In spite of the huge investment by the successive Nigerian government and language education aimed at improving the image and performance of students in English language, the performance of the student in English language at basic level of education has never been encouraging in Federal Capital Territory (FCT) specifically. FCT Education Resource Centre results analysis shows that average failure rate in Junior Secondary School Examination (JSSE) English language in the year 2010, 2011, 2012 and 2013 were 52\%, $57 \%, 49 \%$ and $63 \%$ respectively. The Federal Ministry of Education (FGN 2000) has observed that some of the factors responsible for the high failure rate of secondary school students in English language include poor infrastructural facilities, poor quality of teaching staff and poor teaching in schools. Moreover it has been discovered that the persistent poor academic achievement of students in English language and of the subjects is as a result of poor reading habit of the student. This problem of reading usually starts from primary schools and triumph over to secondary schools. Foluso (2004) noted that most of the pupils in many urban, semi-rural and rural schools all over Nigeria that reach upper basic school levels are unable to read and understand grade appropriate material. The results of the FME/UNICEF/UNESCO/MLA study of 1997 (Falayo et al, 1997) revealed that less than a quarter of primary four pupils in Nigerian schools are able to read and comprehend text written in English. The magnitude of this problem causes not only innumerable personal tragedies but also significantly drives instruction down and jeopardizes the future of public schools and children. This has also translated and is manifested in the poor performance of the students in both junior and senior secondary school level. Thus, the study is designed to identify and analyse the word recognition problems in reading among junior secondary school students in Federal Capital Territory (FCT) Abuja.

\section{Purpose of the Study}

The study sought to:

1. Identify and analyse the problem of word recognition in reading among junior secondary school students.

2. Identify and analyse the problem of word recognition in reading among male and female junior secondary school students. 
3. Identify and analyse the problem of word recognition in reading among urban and rural junior secondary school students.

\section{Research questions}

The following research questions were formulated to guide the study.

1. What are the words recognition problems among junior secondary school students in reading?

2. What are the word recognition problems among male and female junior secondary school students in reading?

3. What are the words recognition problems among junior secondary school students in reading?

\section{Hypotheses}

The following null hypotheses were formulated and tested at 0.05 level of significance.

HO1: There is no significant difference between the mean ratings of male and female junior secondary school students on word recognition in identification of reading problems.

$\mathrm{HO}$ : There is no significant difference between the mean ratings of urban and rural secondary school stud on word recognition in identification of reading problems.

\section{Research Methods}

The study adopted a descriptive survey design. It is aimed at collecting data and describing the characteristics, features of facts about a given population using questionnaire, interviews and observation as instrument for data collection. The study was carried out in JSS in Federal Capital Territory (FCT). FCT has six area councils. Two Area Councils were purposively selected to represent FCT as Target population. The two Area Councils (Gwagwalada and Kwali Area Councils) are adjacent to each other and have similarities in culture, language and occupation. The target population of this study comprised of 4,535 (2,332 males and 2,203 females or 2,439 urban and 2,096 rural) JSS II students in Gwagwalada and Kwali Area councils. The data were obtained from the office of FCT Education Resource Centre.

The study adopted multi-stage sampling technique. This technique includes: Purposive, stratified sampling technique and simple random sampling technique. Stratified sampling technique was used to stratify the schools into rural and urban schools, while random sampling was used to select eight schools from the two area councils. The schools are co-educational as there are no separate schools for boys and girls at JSS level in the area of study. Eight intact classes which comprised a total of 320 (176 males and 144 females; 173 urban and 147 rural) students were used. In each school, two intact classes of 40 students each were selected using random sampling technique.

Reading passage of eighty three (83) words tests in pronunciation and word recognition was administered to the students. The passage for reading was developed by the researcher based on Junior Secondary School Curriculum (2008). The transcription of the passage for pronunciations was also carried out by the researcher. The reading text served in evaluating the students' ability to recognize and pronounce given words. The students were given the passage to read and the teacher observed the number of times each student committed pronunciation and word recognition errors on each word in the passage. The instrument for this study was subjected to face validity by three experts in language education from Federal Capital Territory College of Education Zuba, Abuja. The reliability coefficient of the instrument was found to be .75 using the Cronbach Alpha formula.

The English teachers administered the instrument to the students in their respective schools and classes. The reading test was administered on a student for each of the problem areas in word recognition, the average of the problem areas was determined. The data collected for this study was analysed as follows; frequency counts and mean were used to answer all the research questions. The two hypotheses were tested using t-test statistics at .05 level of significance. For decision making, errors with frequency value of 500 and mean value of 10.00 and above are considered frequently occur errors and errors of frequency value of less than 500 with mean value of less than 10 means are considered not frequent. For the Null hypotheses, when the t-calculated was greater than the critical table value, the null hypothesis was rejected, but if otherwise, the null hypothesis was accepted. 


\section{Results}

\section{Research question 1}

What are the words recognition problems among junior secondary school students in reading?

Table 1: Frequency, mean and standard deviation of word recognition problems among junior secondary school students in reading

\begin{tabular}{|c|c|c|c|c|c|c|}
\hline \multirow[t]{2}{*}{$\mathrm{S} / \mathrm{N}$} & \multirow[t]{2}{*}{ Reading problems types } & \multirow{2}{*}{$\begin{array}{l}\text { No. of } \\
\text { words }\end{array}$} & \multirow{2}{*}{$\begin{array}{l}\text { Total } \\
\text { possible } \\
\text { problem }\end{array}$} & \multicolumn{3}{|c|}{ No of problems made } \\
\hline & & & & freq & mean & SD \\
\hline 1 & Inability to connect sound speech to letters & 83 & 26560 & 7516 & 23.49 & 8.79 \\
\hline 2 & Inability to recognise letter sequence, accurately and quickly & 83 & 26560 & 12457 & 38.93 & 11.61 \\
\hline 3 & Poor knowledge of alphabets & 83 & 26560 & 16773 & 52.42 & 14.63 \\
\hline 4 & Lack of phonetic awareness & 83 & 26560 & 13563 & 42.38 & 12.45 \\
\hline 5 & Sound- letter relation and their sequence of introduction & 83 & 26560 & 16230 & 50.71 & 13.07 \\
\hline 6 & Poor spelling knowledge & 83 & 26560 & 10045 & 31.39 & 10.35 \\
\hline 7 & Mis- matching of letters & 83 & 26560 & 8523 & 26.63 & 9.54 \\
\hline 8 & Inability to see letters in appropriate ways (backward or upside down) & 83 & 26560 & 4578 & 14.31 & 5.89 \\
\hline 9 & Mis- matching of words using shapes & 83 & 26560 & 3564 & 11.14 & 5.23 \\
\hline 10 & Breaking of words into syllables & 83 & 26560 & 12905 & 40.34 & 12.01 \\
\hline 11 & Inability to distinguish between vowels & 83 & 26560 & 13673 & 42.73 & 12.57 \\
\hline 12 & Skipping of words & 83 & 26560 & 5689 & 17.77 & 7.69 \\
\hline
\end{tabular}

Key:

Number of students $=320$.

Total possible errors $=$ Number of students $x$ number of words $(83 \times 320=26560)$

Frequency of the errors committed $=$ Total No of errors committed by all the students on the error type.

Mean of error committed $=$ Frequency of error committed $\div$ total number of students

The data presented in the table 1 reveals that the frequency and mean of the number of problems made by the students on word recognition on item 1 are 7516 and 23.49, on item 2 are 1247 and 38.93, on item 3 are 16773 and 52.42, on item 4 are 13563 and 42.38, item 516230 and 50.71, on item 610045 and 31.59 on item 7 8523: 26.63 item 84578 and 14.31 on item 8.3564: 11.14, item 1012905 and 40.34; on item 1113673 and 42.73. and the frequency and mean of the error committed in word recognition on item 12 are 5689 and 17.77 with the result, the table reveal that the student committed more errors on word recognition on item 3,4,5,10 and 11 while few error were committed in word recognition on item 9,8,6 and 12.

\section{Research question 2} reading?

What are the words recognition problems among male and female junior secondary school students in

Table 2: Frequency, mean and standard deviation of word recognition problems among male and female junior secondary school students $\mathrm{n}$ reading

\begin{tabular}{|c|c|c|c|c|c|c|c|}
\hline \multirow[t]{3}{*}{$\mathrm{S} / \mathrm{N}$} & \multirow[t]{3}{*}{ Word recognition types } & \multicolumn{6}{|c|}{ Errors committed on word recognition } \\
\hline & & \multicolumn{3}{|c|}{ Male $\mathrm{N}=176$} & \multicolumn{3}{|c|}{ Female N=144 } \\
\hline & & freq & mean & SD & freq & mean & SD \\
\hline 1 & Inability to connect sound speech to letters & 4510 & 25.63 & 9.80 & 3006 & 20.88 & 9.78 \\
\hline 2 & Inability to recognize letter sequence, accurately and quickly & 7361 & 41.61 & 10.21 & 5441 & 37.58 & 10.31 \\
\hline 3 & Poor knowledge of alphabets & 7043 & 47.16 & 13.80 & 5269 & 36.59 & 16.73 \\
\hline 4 & Lack of phonetic awareness & 7460 & 42.39 & 13.15 & 6103 & 42.38 & 12.91 \\
\hline 5 & Sound- letter relations and their sequence & 8467 & 48.11 & 13.47 & 6530 & 45.35 & 13.51 \\
\hline 6 & Poor spelling knowledge & 6730 & 38.24 & 12.15 & 4755 & 33.02 & 12.31 \\
\hline 7 & Mis- match of letters & 5856 & 33.27 & 11.82 & 4576 & 31.78 & 9.10 \\
\hline 8 & $\begin{array}{l}\text { Inability to see letters in appropriate ways (backward or upside } \\
\text { down) }\end{array}$ & 2473 & 14.05 & 6.71 & 1963 & 13.63 & 6.66 \\
\hline 9 & Mis- match of words using shapes & 2388 & 13.57 & 5.90 & 1176 & 12.17 & 5.83 \\
\hline 10 & Breaking into syllabus & 7098 & 40.33 & 12.05 & 5807 & 40.33 & 11.93 \\
\hline 11 & Inability to distinguish between vowels & 5273 & 29.97 & 10.19 & 5727 & 39.77 & 11.21 \\
\hline \multirow[t]{2}{*}{12} & Skipping of words & 3588 & 20.39 & 7.65 & 2853 & 19.81 & 6.35 \\
\hline & Grand mean and standard deviation & 5832 & 33.33 & 10.56 & 4319 & 32.94 & 10.55 \\
\hline
\end{tabular}

Key:

Number of students $=320$.

Total possible errors $=$ Number of students $x$ number of words $(83 \times 320=26560)$

Frequency of the errors committed = Total No of errors committed by all the students on the error type.

Mean of error committed $=$ Frequency of error committed $\div$ total number of students 
The data presented in table 2 indicated the frequency and mean of error committed by male and female students in word recognition in item 1 are 451025.63 an 3006; 20.88 on item 2 are 361; $41: 85$ and 5441; 37.58 , on item 3 7043; 47:16 and 5269:36.59, on item 4 are 7460: 4239 and 6103: 3238 on items 5 8467: 48.11 and 6530: 45.35 on item 6 are 6730:38.24 and 4755:33.02, in item 7 are 5856: 3327 and 19.63, on item 10 are 7098: 40.33 and 5807: 40.33, on item 11 are 52.73: 29.97 and 5727: 39.77, item 12 are 3588: 20.39 and 2853: 19.81.

With this result, the male student committed more error in word recognition than the female sttudents as indicated in their frequency and their means.

\section{Research question 3} reading?

What are the words recognition problems among male and female junior secondary school students in

Table 3: Frequency mean and standard deviation of word recognition problems among urban and rural junior secondary school students in reading?

\begin{tabular}{|c|c|c|c|c|c|c|c|}
\hline \multirow[t]{3}{*}{$\mathrm{S} / \mathrm{N}$} & \multirow[t]{3}{*}{ Word recognition types } & \multicolumn{4}{|c|}{ Problem made } & & \\
\hline & & \multicolumn{3}{|c|}{ Urban $\mathrm{N}=173$} & \multicolumn{3}{|c|}{ Rural N=146 } \\
\hline & & Freq & mean & SD & Freq & mean & SD \\
\hline 1 & Inability to connect sound speech to letters & 3382 & 27.55 & 8.81 & 4134 & 28.12 & 8.93 \\
\hline 2 & Inability to recognise letter sequence, accurately and quickly & 6495 & 39.60 & 14.01 & 6551 & 42.14 & 14.31 \\
\hline 3 & Poor knowledge of alphabets & 7247 & 41.89 & 17.30 & 7538 & 51.8 & 12.51 \\
\hline 4 & Lack of phonetic awareness & 7040 & 40.69 & 15.31 & 7204 & 49.01 & 13.81 \\
\hline 5 & Sound- letter relations and their sequence & 7007 & 40.51 & 13.33 & 74492 & 50.97 & 12.91 \\
\hline 6 & Poor spelling knowledge & 4802 & 27.75 & 13.02 & 4981 & 33.88 & 12.41 \\
\hline 7 & Mis- match of letters & 4688 & 27.10 & 9.06 & 5305 & 36.09 & 8.61 \\
\hline 8 & $\begin{array}{l}\text { Inability to see letters in appropriate ways (backward or upside } \\
\text { down) }\end{array}$ & 2707 & 15.68 & 7.32 & 2747 & 18.69 & 6.07 \\
\hline 9 & Mis- match of words using shapes & 1781 & 10.30 & 7.38 & 1783 & 12.12 & 7.42 \\
\hline 10 & Breaking into syllabus & 7143 & 44.76 & 13.93 & 7233 & 45.12 & 12.81 \\
\hline 11 & Inability to distinguish between vowels & 4329 & 26.76 & 7.88 & 4528 & 30.76 & 12.61 \\
\hline \multirow[t]{2}{*}{12} & Skipping of words & 2801 & 16.77 & 6.92 & 2889 & 18.97 & 10.81 \\
\hline & Grand mean and standard deviation & 5620 & 31.15 & 11.26 & 6683 & 32.6 & 11.10 \\
\hline
\end{tabular}

Key:

Number of students $=320$.

Total possible errors $=$ Number of students $x$ number of words $(83 \times 320=26560)$

Frequency of the errors committed = Total No of errors committed by all the students on the error type.

Mean of error committed $=$ Frequency of error committed $\div$ total number of students

Table 3 shows that the frequency and mean of urban and rural on word recognition in item 1 are 3382: 27:53 and 4134: 28.12, item 2 are 6195: 37.81 and 6551:42.14, items 3 are 7247:4189 and 7538:28.12, item 4 are 8140: 4049 and 7204: 44.01, items 5 are 7008: 40.51 and $7204: 50.97$, on item 6 are $4802: 37.75$ and 4981 : 33.88 on item 7 are 4688:10 and 5305: $36.69: 45.12$, on item 11 are 4329: 25.02 and 4528: 30.76 and on item 12 are 2001: 16.77 and 2889: 18.97.

With this result, the rural students had more problems in word recognition than the urban students as indicated in their frequencies and mean.

\section{Hypothesis 1}

\section{Hypotheses Testing}

$\mathrm{HO}_{1}$ : There is no significant difference between the mean ratings of male and female junior secondary school students in word recognition identification or reading problems

Table 4: $\mathrm{t}$ test analysis of word recognition problems among junior secondary school male and female students in reading.

\begin{tabular}{|l|l|l|l|l|l|l|l|}
\hline Sex & N & Mean & SD & Df & Tcal & Tcrit & Remark \\
\cline { 1 - 3 } Male & 176 & 33.33 & 10.56 & & & & \\
\cline { 1 - 3 } & 144 & 32.94 & 10.55 & & 1.0540 & 1.96 & $\begin{array}{l}\text { Not } \\
\text { significant }\end{array}$ \\
\hline
\end{tabular}

Key: $N=$ Number of students, $S D=$ Standard Deviation

Table 4, indicates that the t-calculated value is 1.054 as against the $t$ - table value which is 1.96 at 0.05 level of significance at 318 degree of freedom. The t- calculated value is less than the table value. Thos implies that the null hypothesis of no significant is accepted. Therefore, there was no statistically significant difference 
between the mean ratings of male and female students in word recognition on identification of reading problems.

\section{Hypothesis 2}

$\mathrm{HO}_{4}$ : There is no significant difference between the mean ratings of the urban and rural junior secondary school students in identification of reading problems

Table 5: t-test analysis of urban and rural junior secondary school students in identification of reading problems

\begin{tabular}{|l|l|l|l|l|l|l|l|}
\hline Location & N & Mean & SD & Df & Tcal & Tcrit & Remark \\
\cline { 1 - 4 } Urban & 173 & 29.63 & 11.26 & & & & \\
\cline { 1 - 3 } & 147 & 34.76 & 11.10 & 318 & 13.6814 & 1.96 & Significant \\
\hline
\end{tabular}

Key: $N=$ Number of students, $S D=$ Standard Deviation

Table 5 shows that the $\mathrm{t}$ - calculated valve is 13.681 as against the $\mathrm{t}$-table value which is 1.96 at 0.05 level of significance at 318 degree of freedom. The $t$-calculated value of 13.6814 is greater than the $t$-table value of 1.96. This implies that the null hypothesis of no significant is rejected. Therefore, there was significant difference between the mean ratings of urban and rural students on word recognition in identification of reading problems.

\section{Discussion of Findings}

The findings of this study reveal that the junior secondary school students committed errors in word recognitions during reading. This finding is also in agreement with the submission of Ajuziem (1991) who stated learner's mistakes and error, in English language, could be as a result of native language influence or transfer. The result of this finding also agreed with Foluso, (2004) who carried out a study on why pupil in secondary schools cannot read and writes, and found out that in ability to recognize written letters has been a major factor affecting the reading skills of secondary school pupil.

Research on word recognitions reveal that students are having problems in recognizing letter sequence accurately and quickly, connecting sound speech to letters and identifying the alphabets. The result further reveal that student lack phonetic awareness, had poor spelling knowledge, find it difficult to match letters appropriately and also to break words into syllables. This result is in agreement with the result of the FME/UNICEF/UNESCO/MLA study of 1997 (Falayo, Makoju, Okebukola, Olabodun and Onuche, 1997) who found out that most of the pupils in Nigerian schools are unable to read and comprehend text written in English. This result is also in agreement with Foluso, (2004). who found out those students who have difficulties in recognizing graded texts and alphabets find reading of comprehension difficult.

The findings of the study of gender in word recognition also revealed that male students had more problems in word recognitions during reading than the female students. This is in line with the submission of Ajuziem (1991) on the identification and analysis of special learning problems in reading and writing who found out those male students had more problem in reading than the female students.

Research on student's location in word recognition also revealed that rural students had more problems in word recognition than the urban students. This is in agreement with the Aboki and Oyetunde (998) who observed that students in the urban areas performed better then students in the rural areas due to poor reading habits of the students, nonconductive learning environment and non-availability of necessary tools that can enhance reading and writing skills in rural areas.

The $t$-test analysis for hypothesis 1 revealed that there was significant difference between the means of error committed by male and female students in word recognition. The non significant difference may be due to the fact that the students were exposed to the same learning environment and conductions. This result was also in consonance with the report of Ajuziem (1991) who argued that students who were exposed to the same learning environment and conductions performed relatively the same in word recognition during reading.

The t-test analysis for hypothesis 2 revealed that there also significant differences between the mean ratings of errors committed by urban and rural students in word recognition. The significant effect as pointed out by Ajuziem (1991) is due to lack of infrastructure facilities, libraries, reading materials, qualified teachers and poor reading habits of students in rural areas. The report is in support of Aboki and Oyetunde (1998) who observed that students that students in the urban areas performed better than rural areas in reading.

\section{Conclusion}

From the findings and discussions on the identification and analysis of reading problems among junior secondary schools, students commit a lot of problems in word recognition during reading. Gender has no significant influence on word recognition while rural students commit more errors in and word recognition than the urban students. 


\section{Recommendations}

Based on the findings of this study the following recommendations are made:

1. The findings of this study reveal that junior secondary students had problems in reading; therefore intensive effort should be made by stakeholders in education to provide solution to these problems. This can only be achieved by encouraging the students through the provision of infrastructural facilities like libraries, classroom, teaching aids and textual materials.

2. Enlightenment campaign, workshop and seminars should be organized for teachers by education authorities- Federal and state ministries of education, universal basic education boards, institutes and college of education. To create awareness of the problem of reading and then sensitize them on the necessity for providing solution to this problems.

3. Teachers should pay particular attention to the teacher of English reading especially those factors which contributes to students poor performance in reading

4. Student should be properly drilled in English language to improve their reading competence and academic performance. Finally government should equip both rural and urban schools with facilities that will aid students in their reading and learn English language effectively.

\section{References}

[1]. Aboki, F. A. \& Oyetunde, T. O. (1998). Teaching Reading in Primary Schools. Vol.1 Jos; LECAPS Publishers.

[2]. Ajuziem, G. N. (1991). Identification of Problems in the Implementation of Oral English Curriculum for Secondary Schools in Imo State. Unpublished M.Ed thesis, University of Nigeria, Nsukka

[3]. Akanbi, T. (2005). Gender difference in achievement in science: A review. Ilorin journal of science education, 1 (2), 29-38.

[4]. Andrew F. F(2010). The Four Language Skills. Retrieved on July 20, 2008 fromhttp://edwebsdu:edu/courses/edutech/html.

[5]. Becker, B.J. (1991). Gender and science achievement: A re-analysis of students forms. Journal of Research in Science Teaching, 26 (2), 141-169.

[6]. Bukoye, R.O. (2000). Career guidance for secondary school students. ibadan: Botolan Educational publishers.

[7]. Coleman, E. (2000). School factors and their effects on Achievement. Ilinoisi Teacher May/June; 162-184

[8]. Cyan, A. .T (2005) Language and Society. Retrieved on July 7, 2009 from http://ouray.cudenver.edu/-slsanforlenstdm.txt.

[9]. Deluxe, A. M. (2004). Strategy for imparting Language skills into primary school Pupils. Retrieved on July 10, 2006, from $\mathrm{http} / /$ :www.amstat.org/publications/jse/v $11 \mathrm{n} 3 /$ mvududu.html.

[10]. Emetaram, U. G. (1991). Functional Reading; The information Bank for quality Education in Nigeria. Literacy and Reading in Nigeria. 5,229-234.

[11]. Federal Republic of Nigeria (2004). National Policy on Education. Lagos: NERDC

[12]. Falayajo, W., Makoju, G. A. E., Okebukola, P. A. O., Olubodun, D. \& Ohuohe, D. (1997). Monitoring of learning-Achievement in Nigerian Primary Schools. A National Report.Lagos; FGN/UNICEF/UNESCO.

[13]. Foluso, K. (2004). Children Emergent reading in English language from theory to practice. Literacy and Reading in Nigeria, 15, 819.

[14]. Gough, P. B., Juel, C. \& Griffith, P. L. (1992). Reading, Spelling and the orthographic. London: Routledge Publishers

[15]. Hamptson, F. (1999). Analysis of oral Reading mecues. Psychological radio research quarterly. 1 (3), 1 -16.

[16]. Hornby, A. S. (2009). Oxford Advanced learner's Dictionary of current English. $5^{\text {th }}$ Wd. New York: Oxford University Press.

[17]. Howden, K, R. (1998). A conceptual basis for ethics in teaching education: Journal of teaching education 6, 5-13.

[18]. Literacy Information and Communication System Assessment Strategies and Reading Retrieved on 15 September, 2014 from https://lincs.ed.gov/readingprofiles/MC_Text_Comprehension.htm

[19]. Lona, J. (2004). Reflective teaching in English Language. Retrieved from http://www.scholar/lib.vt.odu/ejournals/jiev7ni/gokhale.jtev7uI.htm on 7 January, 2008.

[20]. Longe, V. (1989). Teaching to read and understand. In Ubahakwe,E.(Ed.).The teaching of English Studies: Reading for Colleges and Universities, Ibadan: University Press.

[21]. Longman Dictionary of Contemporary English (2009). England: Pearson Education Limited

[22]. Mela, U. T. C. (2009). Conducted a research on the interference of Igbo tense and aspect patterns in English language usage among secondary schools students in Abuja Municipal area council. Unpublished M.Ed Thesis, University of Nigeria, Nsukka.

[23]. Offorma, G. C. (2009). Curriculum across languages. $49^{\text {th }}$ Inaugural Lecture, University of Nigeria, Nsukka.

[24]. Okebukola, F.O. (2000). How differently literate are boys and girls in reading? Educational Perspectives. 5(1)18-22.

[25]. Onibokun, Y. (1980). Achievement motivation disparity between boys and girls in a Nigeria setting. West African Journal of Education. XXI (2), 108-112

[26]. Oyedeji, N.B. (2000). Gender and students' academic performance in selected business subjects in Ilorin metropolis. Journal of Educational Focus, 2 (2), 123-126. 